\title{
Profiling undergraduate students from a Romanian medical university
}

This article was published in the following Dove Press journal:

Neuropsychiatric Disease and Treatment

\section{Radu-Stefan Romosan \\ Liana Dehelean \\ Virgil-Radu Enatescu \\ Ana Cristina Bredicean \\ Ion Papava \\ Catalina Giurgi-Oncu \\ Ana-Maria Romosan}

Department of Neurosciences, "Victor Babes" University of Medicine and Pharmacy, Timisoara, Romania
Correspondence: Liana Dehelean

Department of Neurosciences, "Victor

Babes" University of Medicine and

Pharmacy, 2 Eftimie Murgu Square,

Timisoara 30004I, Romania

$\mathrm{Tel}+4072498 \mathrm{I} 888$

Fax +40 256490626

Email dehelean.liana@gmail.com
Purpose: Medical students' personality traits, emotion regulation strategies, and empathic behavior are considered powerful predictors for their future achievements, professional adjustment, and mental strength. Coping strategies such as "self-blame," "rumination," "catastrophizing," "blaming others," lack of empathy, decreased emotion recognition abilities, and neuroticism are maladaptive and, thus, less desirable traits in medical professionals. The purpose of the study was to comparatively assess and find potential correlations between personality traits, empathy levels, emotion recognition abilities, and cognitive emotion regulation strategies of three medical student samples: general medicine (GM), dental medicine (DM), and general nursing (GN) students.

Patients and methods: This cross-sectional comparative study was conducted throughout the second semester of 2017, during Psychiatry class, on 306 medical undergraduates of the "Victor Babes" University of Medicine and Pharmacy, Timisoara, Romania. Personality was assessed by using Neuroticism-Extraversion-Openness to Experience Five-Factor Inventory (NEO-FFI). Cognitive emotion regulation strategies were identified using the Cognitive Emotion Regulation Questionnaire (CERQ). Empathy quotient (EQ) was used to measure empathy levels. Emotion recognition abilities were evaluated with the Reading the Mind in the Eyes test (RMET).

Results: GM students scored significantly higher than both DM and GN students in blaming others (CERQ) and significantly higher than GN students in "neuroticism" (NEO-FFI). GM and DM students obtained significantly lower scores than their GN colleagues in "agreeableness" (NEO-FFI) and empathy (EQ). Compared to DM students, GN students gave significantly more correct answers in RMET. Neuroticism was associated with less efficient coping mechanisms (self-blame, rumination, catastrophizing, blaming others) and lower empathy scores. Empathy correlated negatively with blaming others and was positively associated with agreeableness and emotion recognition abilities.

Conclusion: The differences found between the student samples can be consequences of several overlapping factors. Certain personality traits may predispose individuals to maladaptive coping responses, increased vulnerability to stress, and lower empathy levels. The results of this study can be viewed as baseline data for future, more comprehensive, longitudinal analyses.

Keywords: undergraduate, education environment, medical education research, dental students, nursing students

\section{Introduction}

Health care professionals, besides having good training, should be - ideally - calm, empathic, but also always alert, capable of controlling their emotions when facing critical situations, with strong coping abilities. ${ }^{1}$

Both empathy and social cognition are of most importance in the medical field. Empathy refers to the ability to comprehend and bond with the emotional state of another person, a multidimensional concept comprising cognitive and affective 
processes. ${ }^{2,3}$ In patient care, empathy encompasses the "ability to understand the patient's inner experiences and perspective and the capability to communicate this understanding." 4 Therefore, recognizing emotions in others is essential in order to establish a successful interaction between patients and future health care professionals. According to previous studies, facial expressions are considered the most important elements of emotion communication..$^{5}$ The eye region has been reported to bear most of the information concerning the emotional state of a person.,7

Emotion regulation strategies refer to those particular psychological mechanisms that people use to deal with their emotions, which can be done consciously, or unconsciously. ${ }^{8}$ Emotion dysregulation indicates the various troublesome manners in which individuals face and react to emotional problems, and has been associated, in certain cases, with depressive symptoms, substance abuse, anxiety, and aggression. ${ }^{9}$ The medical act cannot be detached from emotional involvement, and since certain emotion regulation mechanisms are known to be maladaptive, the way in which students process and regulate their emotions becomes very important, because it can affect their physical and mental well-being. ${ }^{10}$

In order to succeed during their medical training and later on in the medical profession, a certain blend of personality traits is desired in students. ${ }^{11,12}$ The Big Five Personality dimension includes a broad variety of personality features and is extensively used by researchers for the study of predictors for academic achievement. ${ }^{13,14}$

Research on Romanian medical, dental, and nursing undergraduates is very scant, literature data providing little information on the subject. Therefore, the main objective of the present study was to offer insight to Romanian medical students' personalities, empathy levels, emotion recognition skills, and coping strategies by comparatively assessing these particular traits in three student samples (general medicine [GM], dental medicine [DM], and general nursing [GN] students).

Because the abilities to empathize, recognize emotions in others, and access and implement emotion regulation strategies in adjustable and efficient ways can vary substantially between individuals, ${ }^{15}$ it is possible that emotion regulation strategies, empathy, and emotion recognition skills are linked to certain aspects of personality. Consequently, another objective of this study was to explore the potential relationship between students' personalities, empathy levels, emotion recognition abilities, and emotion regulation (coping) mechanisms. Considering that particular personality features can predispose individuals to respond and regulate their emotions in specific ways, more or less maladaptive, ${ }^{16-18}$ we anticipate finding positive associations between emotion dysregulation and neuroticism. By contrast, positive correlations between extraversion, openness to experience, and adaptive, problem-focused emotion regulation strategies are assumed. Since empathy and social cognition are essential for interpersonal relationships, we expect to obtain positive correlations between scores for empathy and personality features that stimulate interpersonal relationships (such as agreeableness and openness to experience), and negative correlations between scores for empathy and personality traits such as neuroticism.

The present study hopes to provide the healthcare academic system with data regarding psychological profiles for Romanian GM, DM, and GN students. Also, these results will represent baseline data for future longitudinal analyses after the students graduate and enroll in the medical care workforce.

\section{Materials and methods \\ Setting}

The Timisoara Victor Babes University of Medicine and Pharmacy consists of three faculties, each of them with their own several subspecialties: the Faculty of Medicine (GM - 6 years, Registered Nurses in GM - 4 years, Balneophysio-kineto-therapy and recuperation -3 years, Radiology and Imaging -3 years, Nutritional Dietetics -3 years), the Faculty of DM (DM - 6 years, Dental Technique -3 years, Dental Hygiene -3 years), and the Faculty of Pharmacy (Pharmacy -5 years, Pharmaceutical Assistants -3 years). Foreign students also have the possibility of studying Medicine and DM in English or French (these students were not included in the present study). Each year, $\sim 600$ students graduate from the Faculty of DM and the Faculty of Medicine (GM and GN).

The study was conducted on Romanian undergraduates from the Timisoara Victor Babes University of Medicine and Pharmacy during Psychiatry class. Psychiatry is a compulsory discipline for GM, GN, and DM students. GM and GN students study Psychiatry in their terminal year (the sixth year for GM and the fourth year for GN). DM students study Psychiatry during their fourth year. All students attending the Psychiatry class in the second semester of the academic year 2016-2017 were invited to take part in the present research ( $\sim 325$ students).

\section{Participants}

The minimum sample size was calculated using the G-power software (version 3.1; Heinrich Heine University, Duesseldorf, Germany). Based on a previous analysis of a 
smaller sample of students, and also considering Cochran's sampling techniques, ${ }^{19}$ a minimum of 289 participants was estimated to be sufficient so as to detect a medium effect size $(\mathrm{f}=0.25)$, with an error probability (alpha) of 0.05 , a power of 0.9 , and an addition of $15 \%$ (in order to account for missing data).

Three hundred and six Romanian GM, GN, and DM undergraduates attending the Timisoara Victor Babes University of Medicine and Pharmacy agreed to participate in this cross-sectional comparative study ( $94 \%$ of the total number of students approached and $51 \%$ of the total number of students that graduate each year): sixth-year GM students $(n=105)$, fourth-year DM students $(n=103)$, and fourth-year GN students $(n=98)$. All students were informed about the purpose of the current research and gave their written informed consent prior to participation. The study was approved by the Victor Babes University of Medicine and Pharmacy Research Ethics Committee (reference number: 17/2017) and was conducted according to the principles stated in the Declaration of Helsinki for experiments involving human beings.

\section{Procedure}

Participants were invited to complete four self-report questionnaires: personality traits were assessed with the Neuroticism-Extraversion-Openness to Experience FiveFactor Inventory (NEO-FFI); cognitive emotion regulation strategies were identified with the Cognitive Emotion Regulation Questionnaire (CERQ); empathy levels were measured using the empathy quotient (EQ); and emotion recognition abilities were evaluated with the "Reading the Mind in the Eyes" test (RMET). All the aforementioned instruments were validated, showing high reliability and good internal consistency.

\section{Personality traits}

The Big Five Personality traits (neuroticism, extraversion, openness to experience, agreeableness, and conscientiousness) were evaluated using the Romanian version of the 60 -item NEO-FFI. NEO-FFI ${ }^{20}$ is a shortened version of the 240-item revised NEO Personality Inventory developed by McCrae and Costa in $1989,{ }^{21}$ and is one of the most frequently used measures of the five factor model. Following the five factor model, possibly the most accepted and increasingly applied personality model in medical education, the basic traits of personality are neuroticism (ie, the tendency to experience negative/unpleasant emotions such as anxiety, anger, disgust, depression, to exhibit impulse control and difficulties in managing stress), extraversion (ie, the tendency to actively enroll in social situations and to be communicative, sociable, active, bold, and assertive), openness to experience (ie, the tendency to be creative, curious, open to adventure, intense emotions, and unusual ideas), agreeableness (ie, the tendency to be compassionate, kind, altruistic, flexible, tolerant, goodnatured, helpful, generous, and fair), and conscientiousness (ie, the tendency to be organized, disciplined, dependable, methodical, but also stubborn and obsessive in particular situations). ${ }^{22}$ NEO-FFI demonstrated satisfactory validity and proved its usefulness in various contexts. ${ }^{22}$ The scale has a good internal consistency and a high test-retest reliability. ${ }^{23}$ NEO-FFI is designed to take up to 15 minutes per assessment. Each of the 60 items was rated by the participants on a 5-point Likert-type scale ( $1=$ strongly disagree, $5=$ strongly agree $)$.

\section{Cognitive emotion regulation}

The Romanian version of the CERQ, developed by Garnefski and Kraaij in $2007,{ }^{24}$ was used to identify the cognitive emotion regulation strategies (or cognitive coping strategies) that students use after experiencing negative situations or life events. CERQ showed a substantial factorial validity and high reliability, being a useful tool for the study of individual factors related to emotional problems. ${ }^{25}$ CERQ is a multidimensional 36-item self-report questionnaire which assesses the use of nine cognitive coping strategies. Five of them are considered to be generally adaptive strategies (acceptance, putting into perspective, positive refocusing, refocus on planning, and positive reappraisal), while four are known as generally maladaptive mechanisms (selfblame, rumination, catastrophizing, and blaming others). ${ }^{24}$ Each item is rated on a 5-point Likert-type scale ( $1=$ almost never, $5=$ almost always) and subscale scores are calculated by summing the item scores that correspond to the related subscale (the subscales have scores ranging from 4 to 20). Higher subscale scores mean greater frequency in engaging in corresponding cognitive coping strategies.

\section{Empathy}

The Romanian version of the EQ, developed by BaronCohen and Wheelwright in 2004, ${ }^{26}$ was used to measure the level of empathy. EQ is a 60-item self-report inventory with 40 questions empathy-related and 20 filler questions, each scored on a 4-point Likert-type scale ( $1=$ totally agree, $4=$ totally disagree). Each of the 40 items related to empathy is associated with a score of 0,1 , or 2 ; the filler questions score 0 . Total scores may range from 0 to 80 (the higher the score, the higher the empathy level). Studies show that EQ has a good validity and that it is a reliable scale for measuring empathy. ${ }^{27}$ 


\section{Social cognition}

In order to appraise the ability to understand other people's mental states we used the Romanian revised version of the RMET developed by Baron-Cohen et al. ${ }^{2}$ The revised version appears to be superior to the earlier version, showing acceptable validity and reliability. ${ }^{28,29}$ The test is designed to detect subtle impairments in social acuity both in normal intelligent adults and in patients. It is comprised of 36 eye-region photographs of both males and females. Each photograph has four complex mental state descriptors printed around it (eg, "serious," "alarmed," "bewildered," and "ashamed"), and only one of them describes the correct mental state of the subject in the photo. Participants were asked to choose which of the four words defines best what the subject in the photograph is feeling/thinking. Each photo was shown for 10 seconds. The test was scored by summing the correct number of answers given by each participant (maximum score per student: 36 ).

Both EQ and RMET can be freely downloaded from the Internet for use in research (https://www.autismresearchcentre.com/arc tests).

\section{Statistical analysis}

Data were analyzed using IBM SPSS Statistics (version 20; IBM Corporation, Armonk, NY, USA). The Shapiro-Wilk normality test revealed a non-Gaussian data distribution (Table 1) and therefore, in order to compare groups, we used nonparametric tests (the Mann-Whitney $U$ test with the Bonferroni correction, the Kruskal-Wallis test, followed by the Dunn post hoc procedure). Associations between scores obtained in empathy, social cognition, cognitive coping strategies, and the five domains of personality were analyzed using Spearman's correlation coefficient. To check for differences between categorical variables, the $\chi^{2}$ (chi-square) test was applied. The level of significance was set at 0.05 . All results were two-tailed.

\section{Results}

The study included 306 Romanian medical students, which we divided into three samples: 105 GM students, 103 DM students, and 98 GN students.

Sample characteristics are presented in Table 2. None of the students were married, or had children. There were significant differences $\left(\chi^{2}=15.946, p<0.0001\right)$ between the three student samples regarding gender distribution (the male to female ratio was 1:2.3 in the GM sample, 1:1.5 in the DM sample, and 1:5.5 in the GN sample).

Because of the non-Gaussian distribution of the variables, numerical data are expressed by using medians and extreme
Table I Results of the Shapiro-Wilk test for normality of distribution

\begin{tabular}{|c|c|c|c|c|}
\hline $\begin{array}{l}\text { Sample } \\
\text { characteristics }\end{array}$ & Students & $\mathbf{N}$ & $\begin{array}{l}\text { Shapiro-Wilk } \\
\text { test statistics }\end{array}$ & $p$-value \\
\hline \multirow[t]{3}{*}{ Age } & GM & 105 & 0.729 & $<0.000$ I \\
\hline & DM & 103 & 0.667 & $<0.0001$ \\
\hline & $\mathrm{GN}$ & 98 & 0.557 & $<0.0001$ \\
\hline \multirow[t]{3}{*}{ CERQ: self-blame } & GM & 105 & 0.761 & $<0.0001$ \\
\hline & DM & 103 & 0.954 & 0.001 \\
\hline & GN & 98 & 0.813 & $<0.000$ I \\
\hline \multirow[t]{3}{*}{ CERQ: acceptance } & GM & 105 & 0.904 & $<0.0001$ \\
\hline & DM & 103 & 0.939 & $<0.000$ I \\
\hline & $\mathrm{GN}$ & 98 & 0.932 & $<0.000$ I \\
\hline \multirow[t]{3}{*}{ CERQ: rumination } & GM & 105 & 0.956 & 0.002 \\
\hline & DM & 103 & 0.951 & 0.001 \\
\hline & $\mathrm{GN}$ & 98 & 0.969 & 0.019 \\
\hline CERQ: positive & GM & 105 & 0.856 & $<0.0001$ \\
\hline \multirow[t]{2}{*}{ refocusing } & DM & 103 & 0.878 & 0.047 \\
\hline & $\mathrm{GN}$ & 98 & 0.944 & $<0.0001$ \\
\hline CERQ: refocus on & GM & 105 & 0.968 & 0.012 \\
\hline \multirow[t]{2}{*}{ planning } & DM & 103 & 0.971 & 0.021 \\
\hline & GN & 98 & 0.896 & $<0.000$ I \\
\hline CERQ: positive & GM & 105 & 0.970 & 0.018 \\
\hline \multirow[t]{2}{*}{ reappraisal } & DM & 103 & 0.924 & $<0.000$ I \\
\hline & $\mathrm{GN}$ & 98 & 0.876 & $<0.000$ I \\
\hline CERQ: putting into & GM & 105 & 0.944 & $<0.0001$ \\
\hline \multirow[t]{2}{*}{ perspective } & DM & 103 & 0.972 & 0.029 \\
\hline & $\mathrm{GN}$ & 98 & 0.840 & $<0.000$ I \\
\hline CERQ: & GM & 105 & 0.637 & $<0.000$ I \\
\hline \multirow[t]{2}{*}{ catastrophizing } & DM & 103 & 0.866 & $<0.000$ I \\
\hline & GN & 98 & 0.888 & $<0.0001$ \\
\hline CERQ: blaming & GM & 105 & 0.915 & $<0.0001$ \\
\hline \multirow[t]{2}{*}{ others } & DM & 103 & 0.917 & $<0.000$ I \\
\hline & GN & 98 & 0.831 & $<0.0001$ \\
\hline NEO-FFI: & GM & 105 & 0.882 & $<0.0001$ \\
\hline \multirow[t]{2}{*}{ neuroticism } & DM & 103 & 0.928 & 0.041 \\
\hline & $\mathrm{GN}$ & 98 & 0.949 & 0.001 \\
\hline NEO-FFI: & GM & 105 & 0.949 & $<0.000$ I \\
\hline \multirow[t]{2}{*}{ extraversion } & DM & 103 & 0.937 & $<0.000$ I \\
\hline & $\mathrm{GN}$ & 98 & 0.858 & $<0.0001$ \\
\hline NEO-FFI: openness & GM & 105 & 0.905 & $<0.0001$ \\
\hline \multirow[t]{2}{*}{ to experience } & DM & 103 & 0.951 & 0.001 \\
\hline & $\mathrm{GN}$ & 98 & 0.877 & $<0.0001$ \\
\hline NEO-FFI: & GM & 105 & 0.957 & 0.002 \\
\hline \multirow[t]{2}{*}{ agreeableness } & DM & 103 & 0.892 & $<0.0001$ \\
\hline & GN & 98 & 0.932 & $<0.0001$ \\
\hline NEO-FFI: & GM & 105 & 0.946 & $<0.000$ I \\
\hline \multirow[t]{2}{*}{ conscientiousness } & $\mathrm{DM}$ & 103 & 0.766 & $<0.0001$ \\
\hline & $\mathrm{GN}$ & 98 & 0.946 & $<0.0001$ \\
\hline \multirow[t]{3}{*}{ EQ } & GM & 105 & 0.888 & $<0.0001$ \\
\hline & DM & 103 & 0.957 & 0.002 \\
\hline & $\mathrm{GN}$ & 98 & 0.962 & 0.006 \\
\hline \multirow[t]{3}{*}{ RMET } & GM & 105 & 0.888 & $<0.0001$ \\
\hline & DM & 103 & 0.847 & $<0.0001$ \\
\hline & GN & 98 & 0.803 & $<0.0001$ \\
\hline
\end{tabular}

Abbreviations: GM, general medicine; DM, dental medicine; GN, general nursing; CERQ, Cognitive Emotion Regulation Questionnaire; NEO-FFI, NeuroticismExtraversion-Openness to Experience Five-Factor Inventory; EQ, empathy quotient; RMET, Reading the Mind in the Eyes test. 
Table 2 Sample characteristics

\begin{tabular}{|l|l|l|l|l|l|l|}
\hline \multirow{2}{*}{ Sample characteristics } & \multicolumn{2}{l|}{ GM students } & \multicolumn{1}{l|}{ DM students } & \multicolumn{1}{l|}{ GN students } \\
\cline { 2 - 7 } & $\mathbf{N}$ & $\%$ & $\mathbf{N}$ & N & $\%$ \\
\hline Gender & 32 & 30.5 & 42 & 40.8 & 15 & 15.3 \\
\hline Males & 73 & 69.5 & 61 & 59.2 & 83 & 84.7 \\
\hline Females & 73 & $23(22-29)$ & & $22(22-35)$ \\
\hline Age in years, median (range) & $25(24-28)$ &
\end{tabular}

Abbreviations: GM, general medicine; DM, dental medicine; GN, general nursing.

values. Median scores and extreme values for personality traits, emotion regulation strategies, empathy, and emotion recognition skills for the three student samples are also shown in Table 3.

The Mann-Whitney $U$ test showed that GM students were older not only than DM students $(\mathrm{U}=749.5, \mathrm{Z}=-11.03$, $p<0.0001)$, but also than $\mathrm{GN}$ students $(\mathrm{U}=1,266, \mathrm{Z}=-9.535$, $p<0.0001)$. There were no significant differences in age between DM and GN students. We also did not find significant differences concerning age between male and female students.

Compared to female students, males obtained significantly lower scores in rumination $(\mathrm{U}=7,928.5, \mathrm{Z}=-2.482, p=0.013)$, "positive refocusing" ( $\mathrm{U}=8,155.5, \mathrm{Z}=-2.149, p=0.032)$, catastrophizing ( $\mathrm{U}=7,888, \mathrm{Z}=-2.559, p=0.01)$, empathy $(\mathrm{U}=6,014.5, \mathrm{Z}=-5.185, p<0.0001)$, and gave considerably less correct answers in the RMET (U=6,495.5, $\mathrm{Z}=-4.514$, $p<0.0001$ ). Males scored significantly higher than females only in blaming others $(\mathrm{U}=7.357, \mathrm{Z}=-3.29, p=0.001)$.

\section{Comparison between the three student samples}

Because of the non-normal data distribution, we used the Kruskal-Wallis test to check for differences in scale scores (CERQ, NEO-FFI, EQ, RMET) between the three student samples. The test revealed significant differences between students regarding the following: blaming others, neuroticism, agreeableness, EQ score, and number of correct answers in RMET (Table 4). Dunn's nonparametric comparison for post hoc testing, performed after the Kruskal-Wallis test, showed that GM students scored significantly higher than both DM and GN students in blaming others $(p<0.0001)$ and significantly higher than GN students in neuroticism $(p=0.015)$. It also revealed that GN students obtained significantly higher scores than their GM and DM colleagues in agreeableness $(p<0.0001)$ and empathy $(p<0.0001)$. When compared to GN students, DM students scored significantly higher only in blaming others $(p<0.0001)$ and significantly lower in $\operatorname{RMET}(p=0.019)$.

Table 3 Median scores (and extreme values) obtained by the three student samples

\begin{tabular}{|c|c|c|c|c|c|c|c|}
\hline \multirow[t]{2}{*}{ Scale } & \multirow[t]{2}{*}{ Scale dimensions } & \multicolumn{2}{|c|}{ GM students } & \multicolumn{2}{|l|}{ DM students } & \multicolumn{2}{|c|}{ GN students } \\
\hline & & $\begin{array}{l}\text { Males } \\
(\mathrm{N}=32)\end{array}$ & $\begin{array}{l}\text { Females } \\
(\mathrm{N}=73)\end{array}$ & $\begin{array}{l}\text { Males } \\
(\mathrm{N}=42)\end{array}$ & $\begin{array}{l}\text { Females } \\
(\mathrm{N}=61)\end{array}$ & $\begin{array}{l}\text { Males } \\
(\mathrm{N}=15)\end{array}$ & $\begin{array}{l}\text { Females } \\
(\mathrm{N}=83)\end{array}$ \\
\hline \multirow[t]{9}{*}{ CERQ } & Self-blame & $7(4-15)$ & $7(4-20)$ & $8(4-15)$ & $9(4-12)$ & $7(5-20)$ & $8(4-20)$ \\
\hline & Acceptance & $10(5-13)$ & $10(7-19)$ & $10.5(9-13)$ & II (7-13) & II (9-I4) & $10(8-15)$ \\
\hline & Rumination & $10(4-13)$ & $9(4-20)$ & $9.5(5-17)$ & II (4-20) & $10(5-13)$ & $10(7-15)$ \\
\hline & Positive refocusing & $10.5(4-13)$ & $11(4-13)$ & $9(4-17)$ & II (4-I8) & $9(5-14)$ & $10(7-15)$ \\
\hline & Refocus on planning & $12(5-20)$ & $12(4-20)$ & $12(7-19)$ & $12(8-20)$ & $12(9-18)$ & $12(8-20)$ \\
\hline & Positive reappraisal & II (4-20) & $12(4-20)$ & $11(8-17)$ & $12(8-20)$ & $12(8-18)$ & II (8-20) \\
\hline & Putting into perspective & $13(6-19)$ & II (9-19) & $12.5(4-19)$ & $12(4-19)$ & $12(10-20)$ & II (9-20) \\
\hline & Catastrophizing & $6(4-8)$ & $6(4-20)$ & $5(4-11)$ & $6(4-15)$ & $5(4-10)$ & $6(4-11)$ \\
\hline & Blaming others & $13(9-20)$ & II (7-20) & $7(4-9)$ & $7(4-9)$ & $5(4-9)$ & $5(4-9)$ \\
\hline \multirow[t]{5}{*}{ NEO-FFI } & Neuroticism & $22(13-38)$ & $23(13-58)$ & $21.5(4-38)$ & $23(7-39)$ & $17(8-37)$ & $18(4-39)$ \\
\hline & Extraversion & $28.5(16-42)$ & $29(14-44)$ & $27(19-45)$ & $28(20-42)$ & $31(17-36)$ & $29(17-39)$ \\
\hline & Openness to experience & $28(5-43)$ & $30(5-43)$ & $29(17-49)$ & $28(16-53)$ & $28(12-36)$ & $30(13-39)$ \\
\hline & Agreeableness & $29(15-45)$ & $29(10-46)$ & $29(12-39)$ & $29(13-53)$ & $39(27-57)$ & $45(17-59)$ \\
\hline & Conscientiousness & $30(2|-4|)$ & $33(15-57)$ & $30(24-56)$ & $30(25-57)$ & $32(28-4 I)$ & $34(24-57)$ \\
\hline RMET (correct answers) & & $23.5(13-33)$ & $30(15-34)$ & $24.5(22-35)$ & $27(22-35)$ & $26(25-33)$ & $27(25-36)$ \\
\hline $\mathrm{EQ}$ & & $27.5(24-45)$ & $33(24-59)$ & $32(15-54)$ & 39 (15-59) & $4 \mathrm{I}(23-55)$ & $46(26-59)$ \\
\hline
\end{tabular}

Abbreviations: GM, general medicine; DM, dental medicine; GN, general nursing; CERQ, Cognitive Emotion Regulation Questionnaire; NEO-FFI, Neuroticism-ExtraversionOpenness to Experience Five-Factor Inventory; RMET, Reading the Mind in the Eyes test; EQ, empathy quotient. 
Table 4 Results of the Kruskal-Wallis test for differences in scale scores

\begin{tabular}{llll}
\hline Variables & $\begin{array}{l}\text { Dimensions for each } \\
\text { study variable }\end{array}$ & Kruskal-Wallis H & p-value \\
\hline CERQ & Self-blame & 6.243 & 0.063 \\
& Acceptance & 4.96 I & 0.084 \\
& Rumination & 1.553 & 0.460 \\
& Positive refocusing & 0.866 & 0.649 \\
& Refocus on planning & 0.745 & 0.689 \\
& Positive reappraisal & 0.016 & 0.992 \\
& Putting into perspective & 1.349 & 0.509 \\
& Catastrophizing & 0.706 & 0.703 \\
& Blaming others & 223.643 & $<0.000$ I** \\
NEO-FFI & Neuroticism & 8.737 & $0.013^{*}$ \\
& Extraversion & 2.284 & 0.319 \\
& Openness to experience & 0.325 & 0.850 \\
& Agreeableness & 68.553 & $<0.000$ I** \\
& Conscientiousness & 4.885 & 0.071 \\
RMET & & 7.929 & $0.019 *$ \\
EQ & & 58.344 & $<0.000$ I** \\
\hline
\end{tabular}

Notes: ${ }^{*} p<0.05 ; * * p<0.001$.

Abbreviations: GM, general medicine; DM, dental medicine; GN, general nursing; CERQ, Cognitive Emotion Regulation Questionnaire; NEO-FFI, NeuroticismExtraversion-Openness to Experience Five-Factor Inventory; RMET, Reading the Mind in the Eyes test; EQ, empathy quotient.

\section{Correlations between scores}

Neuroticism correlated positively with self-blame (Spearman's rho $[\mathrm{rs}]=0.373, p<0.0001$ ), rumination $(\mathrm{rs}=0.423, p<0.0001)$, catastrophizing $(\mathrm{rs}=0.188, p=0.001)$, and blaming others ( $\mathrm{rs}=0.193, p=0.001$ ) in our students. "Openness to experience" correlated positively with positive refocusing ( $\mathrm{rs}=0.165, p=0.004$ ), "refocus on planning" ( $\mathrm{rs}=0.4, p<0.0001$ ), and "positive reappraisal" ( $\mathrm{rs}=0.321$, $p<0.0001)$. Agreeableness correlated negatively with blaming others ( $\mathrm{rs}=-0.42, p<0.0001$ ). EQ score correlated positively with self-blame ( $\mathrm{rs}=0.165, p=0.004)$, agreeableness ( $\mathrm{rs}=0.391, p<0.0001$ ), and number of correct answers given in RMET ( $\mathrm{rs}=0.756, p<0.0001)$. By contrast, EQ correlated negatively with blaming others $(\mathrm{rs}=-0.73, p<0.0001)$ and neuroticism ( $\mathrm{rs}=-0.152, p=0.008)$.

\section{Discussion}

Personality, empathy, social skills, and coping styles are important predictors for the future performance, success, adjustment, and mental health of medical students. This study revealed significant differences between general, dental, and nursing Romanian students in respect to personality, empathy levels, emotion recognition abilities, and emotion regulation (coping) strategies. Compared to the other two student samples, GN students appeared to be the most empathic and obtained the highest scores in agreeableness. This was to be expected, given the fact that having a caring, kind, altruistic, compassionate personality and a good understanding of the feeling of others are vital to the provision of a worthy nursing care. Comparing empathy levels between nursing and other medical students, in a study published in 2011, Nunes et al reported similar results, with GN students obtaining higher scores. ${ }^{30}$

There are some possible explanations for the fact that GM and DM students scored lower in agreeableness and empathy than GN students. One of them may involve dental and GM students' concentration on increasing their technical skills necessary for diagnosing or completing procedures, whilst foregoing social abilities that are, perhaps, perceived as less imperative to their training. This fact may influence these students to center their attention on procedures and less on the patient's emotional problems. ${ }^{31,32}$ By contrast, the contact between a patient and a nurse is the central activity of nursing care, empathy and emotion recognition abilities being essential preconditions for an effective nurse-patient relationship and the understanding of the patient's attitude. ${ }^{33}$ Furthermore, compared to GN students, GM and DM students are perhaps confronted with a greater responsibility, being the ones that have to not only prepare themselves to manage and treat patients in critical conditions, but also manage their own reactions and emotions. It is likely that, in order to do both, they have to set certain limits and thus, they may exhibit less empathy and agreeableness than their nursing colleagues.

Nonetheless, during medical school, undergraduates experience significant amounts of stress. ${ }^{34,35}$ Medical studies are usually perceived as very stressful, students being expected to assimilate large amounts of information in short periods of time, a fact that may involve certain social and personal sacrifices. Certain studies show that the current system applied in medical education can lead to a decline in students' empathy, ${ }^{36-38}$ that accentuates during course progression. ${ }^{30,39}$ Some researchers suggested that this waning is due to high levels of emotional distress or the burden of achieving performance $;{ }^{40}$ others state that the low empathy and increasing cynicism in medical students may reflect certain learned coping or survival strategies. ${ }^{36,38}$ However, it cannot be decided if the changes in self-report empathy are the consequence of medical training or that of the overall moral development. ${ }^{41}$ Of course, not all studies report a reduction in empathy across the medical training program. For example, in 2014, Williams et al compared empathy levels in Australian students and found that first-year students had lower empathy levels than second- and third-year students. ${ }^{42}$ Our study compared EQ scores of medical students from different years of study (nursing and GM students were 
assessed during their terminal year - fourth year for GN and sixth year for GM; DM students were assessed during the fourth year of their six-year study program) and found that the sixth-year GM students had the lowest EQ score. However, we did not measure changes in participants longitudinally. Therefore, future research is needed to see if empathy levels are innately different in GM, DM, and GN students, or if empathy decreases due to the prolonged exposure to medical training (the so-called "hardening of the heart" of the medical students). Another aspect that could be considered is the fact that in this study GM students were older than dental and GN students (as shown in Table 2). Although there are cross-sectional studies that reveal lower empathy levels in older groups compared to younger cohorts, ${ }^{43,44}$ because of the lack of homogeneous published data on the connection between age and empathy in individuals younger than the age of $50,{ }^{45}$ we cannot assume that GM students were less empathic due to their older age. Rather, it is possible that their lower levels of empathy are the product of the confrontation with harsh clinical reality (human illness, death) combined with poorer emotion regulation abilities, or of their shifting from the humanistic side of medicine to the more technological side, primarily used nowadays. ${ }^{31}$

The differences reported in empathy and emotion recognition abilities between the three student samples can also be explained by the fact that in the GN sample females far outnumbered males (Table 2). The dissimilarities found in empathy levels and emotion recognition skills between the student samples may as well be the product of differences in courses or teaching techniques, nurses possibly being introduced to a more empathy-based schooling.

Female students had significantly higher empathy scores and emotion recognition abilities compared to males, which is consistent with other findings, ${ }^{36,46}$ and supporting the theory on women's understanding of others mental states and tolerant attitudes. ${ }^{47}$ Besides the differences found between males and females regarding empathy and emotion recognition skills, females scored higher both in adaptive and in maladaptive coping strategies compared to males (not only in rumination and catastrophizing, but also in positive refocusing), a result expected considering previous research. ${ }^{48}$ This suggests that females are more conscious and more inclined to connect with their emotions.

One could also argue that the obtained results may also be influenced by the selection process of each studied student cohort. However, all students from the Timisoara Victor Babes University of Medicine and Pharmacy that accepted to complete the four questionnaires during Psychiatry class were included in this study. Selection criteria were solely based on students' willingness to participate. Moreover, admission in a Romanian medical university, regardless of the chosen subspecialization, is only based on passing a written biology and a chemistry examination. The selection process for future GM, DM, or GN students does not include a psychological testing for empathy, personality dimensions, or emotion regulation strategies. Therefore, there is no way of knowing if there are more empathic, "agreeable," or healthier stress-coping students enrolled in the nursing programs to begin with.

The phenomenon of professional enculturation is another factor that might influence the results. Unfortunately, the impact of this phenomenon cannot be measured.

Assessing personality features and coping mechanisms can be helpful in identifying individuals that are more vulnerable to stress. Research shows that personality characteristics can be predictors for different coping styles. ${ }^{49}$ Similar to other studies,${ }^{50}$ in our research, neuroticism seemed to be associated with less efficient coping mechanisms (self-blame, rumination, catastrophizing, and blaming others), whereas openness to experience appeared to be positively correlated with active, problem-focused coping and emotion-focused coping (positive refocusing, refocus on planning, and positive reappraisal). In GM students, higher scores than their dental and nursing colleagues in neuroticism may explain the susceptibility for using significantly more often blaming others as a coping strategy, suggesting that these students have the tendency to experience a mixture of disruptive thoughts and emotions and are, therefore, more prone to engage in maladaptive coping responses.

Previous studies found positive associations between empathy and sociability, agreeableness and openness to experience, ${ }^{12}$ and also between empathy and "conscientiousness." $51 \mathrm{We}$, as well, obtained a positive correlation between empathy and agreeableness, but no significant associations between empathy and conscientiousness or openness to experience. Although Eysenck detected a positive correlation between empathy and neuroticism, ${ }^{52}$ in our study, empathy correlated negatively with neuroticism and blaming others, thus supporting the theory that neuroticism is negatively linked with consideration for others and prosocial behavior. ${ }^{53}$

\section{Limitations}

Participants came from one medical university (with a relatively homogenous student population) and therefore, despite its moderate size, the sample is not representative of the Romanian medical student population as a whole. Other limitations are the use of self-report measures for personality and empathy and the fact that the student samples were 
gender nonhomogeneous. The use of self-report measurements, especially for empathy and personality, may represent an important subject of biases, taking into account the respondents' propensity to offer what they believe to be the "ideal" or "correct" answer. Participants were informed that only truthful answers (and not what they think an ideal answer would be) would benefit this study. However, this still may not be enough to guarantee a sincere self-appreciation. It is possible that the results would have been different if measurements were taken from observations of the students interacting directly with patients. The cross-sectional design of the study represents another limitation, a longitudinal assessment possibly offering different results.

Results of the present research can be viewed as a starting point for other, more comprehensive longitudinal studies that may use larger and more diverse student samples.

\section{Conclusion}

Significant differences between the three student samples were observed in this study. In comparison to the other two student samples, GN students were the most empathic and obtained the highest scores in agreeableness. GN students also had lower scores in neuroticism and engaged less in maladaptive coping strategies than both GM and DM students and therefore, appeared more emotionally stable. Compared to DM students, GN students displayed better emotion recognition abilities. Sixth-year GM students had the lowest EQ score. Higher scores than their dental and nursing colleagues in neuroticism and blaming others may suggest that GM students were more vulnerable to stress, with a tendency to use maladaptive emotion regulation strategies.

Females had higher empathy levels, better emotion recognition abilities, and scored higher both in adaptive and in maladaptive coping strategies compared to males (positive refocusing, rumination, catastrophizing).

Neuroticism was associated with less efficient coping mechanisms (self-blame, rumination, catastrophizing, and blaming others), whilst openness to experience was positively correlated with active, problem-focused coping and emotionfocused coping (positive refocusing, refocus on planning, and positive reappraisal). Positive correlations between empathy, agreeableness, and emotion recognition abilities were also found. Empathy correlated negatively with neuroticism and blaming others.

This study seeks to offer baseline information for future longitudinal studies performed after the students graduate and pursue their chosen medical career. Furthermore, the obtained data may also be used in other studies that include students attending universities with nonmedical profiles.

\section{Author contributions}

Radu-Stefan Romosan: study design, acquisition and interpretation of data for the work, drafting and critical revision of the manuscript, approval of the final version of the manuscript, accountable for the accuracy and integrity of the manuscript.

Liana Dehelean, Virgil-Radu Enatescu, Ana Cristina Bredicean, Ion Papava, and Catalina Giurgi-Oncu: significant contribution to the study design and data acquisition, critical revision of the manuscript for intellectual content, approval of the final version of the manuscript, accountable for the accuracy and integrity of the manuscript.

Ana-Maria Romosan: significant contribution to the study design, analysis and interpretation of data for the work, critical revision of the manuscript for intellectual content, approval of the final version of the manuscript, accountable for the accuracy and integrity of the manuscript.

\section{Disclosure}

The authors report no conflicts of interest in this work.

\section{References}

1. Hurwitz S, Kelly B, Powis D, Smyth R, Lewin T. The desirable qualities of future doctors - a study of medical student perceptions. Med Teach. 2013;35(7):1332-1339.

2. Baron-Cohen S, Wheelwright S, Hill J, Raste Y, Plumb I. The "Reading the Mind in the Eyes" Test revised version: a study with normal adults, and adults with Asperger syndrome or high-functioning autism. J Child Psychol Psychiatry. 2001;42(2):241-251.

3. Eisenberg N, Fabes RA, Murphy B, et al. The relations of emotionality and regulation to dispositional and situational empathy-related responding. J Pers Soc Psychol. 1994;66(4):776.

4. Hojat M, Gonnella JS, Nasca TJ, Mangione S, Vergare M, Magee M. Physician empathy: definition, components, measurement, and relationship to gender and specialty. Am J Psychiatry. 2002;159(9):1563-1569.

5. Barrett LF, Salovey P, editors. The Wisdom in Feeling: Psychological Processes in Emotional Intelligence. New York: Guilford Press; 2002.

6. Adams RB Jr, Rule NO, Franklin RG Jr, et al. 2010. Cross-cultural reading the mind in the eyes: an fMRI investigation. J Cogn Neurosci. 2010; 22(1):97-108.

7. Lee SA, Guajardo NR, Short SD, King W. Individual differences in ocular level empathic accuracy ability: the predictive power of fantasy empathy. Pers Individ Dif. 2010;49(1):68-71.

8. Gross JJ. Emotion regulation: affective, cognitive, and social consequences. Psychophysiology. 2002;39(3):281-291.

9. Gratz KL, Dixon-Gordon KL, Whalen D. Dark side of the mood or sweet emotion? Toward a more nuanced understanding of emotional lability. In: Zeigler-Hill V, Marcus DK, editors. The Dark Side of Personality: Science and Practice in Social, Personality, and Clinical Psychology. Washington, DC: American Psychological Association; 2016:168-177.

10. John OP, Gross JJ. Healthy and unhealthy emotion regulation: personality processes, individual differences, and life span development. J Pers. 2004;72(6):1301-1334.

11. Ferguson E, James D, Madeley L. Factors associated with success in medical school: systematic review of the literature. BMJ. 2002; 324(7343):952-957.

12. Griffin B, Wilson I. Associations between the big five personality factors and multiple mini-interviews. Adv Health Sci Educ Theory Pract. 2012;17(3):377-388 
13. Magalhães E, Costa P, Costa MJ. Empathy of medical students and personality: evidence from the five-factor model. Med Teach. 2012; 34(10):807-812.

14. Wilson I, Griffin B, Lampe L, et al. Variation in personality traits of medical students between schools of medicine. Med Teach. 2013;35(11): 944-948.

15. Cole PM, Michel MK, Teti LO. The development of emotion regulation and dysregulation: a clinical perspective. Monogr Soc Res Child Dev. 1994;59(2-3):73-100.

16. Bolger N, Schilling EA. Personality and the problems of everyday life: the role of neuroticism in exposure and reactivity to daily stressors. J Pers. 1991;59(3):355-386.

17. Mroczek DK, Almeida DM. The effect of daily stress, personality, and age on daily negative affect. J Pers. 2004;72(2):355-378.

18. Timmermans T, Van Mechelen I, Nezlek JB. Individual differences in core affect reactivity. Pers Individ Dif. 2009;47(5):510-515.

19. Cochran WG. Sampling Techniques. 2nd ed. New York: John Wiley and Sons Inc; 1963.

20. McCrae RR, Costa PT. A contemplated revision of the NEO five-factor inventory. Pers Individ Dif. 2004;36(3):587-596.

21. McCrae RR, Costa PT. The structure of interpersonal traits: Wiggins's circumplex and the five-factor model. J Pers Soc Psychol. 1989;56(4):586-595.

22. McCrae RR, Costa PT. Validation of the five-factor model of personality across instruments and observers. J Pers Soc Psychol. 1987;52(1): 81-90.

23. Ispas D, Iliescu D, Ilie A, Johnson RE. Exploring the cross-cultural generalizability of the five-factor model of personality: the Romanian NEO PI-R. J Cross Cult Psychol. 2014;45(7):1074-1088.

24. Garnefski N, Kraaij V. The cognitive emotion regulation questionnaire. Eur J Psychol Assess. 2007;23(3):141-149.

25. Perte A, Miclea M. The standardization of the Cognitive Emotional Regulation Questionnaire (CERQ) on Romanian population. Cogn Brain Behav. 2011;15(1):111.

26. Baron-Cohen S, Wheelwright S. The empathy quotient: an investigation of adults with Asperger syndrome or high functioning autism, and normal sex differences. J Autism Dev Disord. 2004;34(3):163-175.

27. Lawrence EJ, Shaw P, Baker D, Baron-Cohen S, David AS. Measuring empathy: reliability and validity of the empathy quotient. Psychol Med. 2004;34(5):911-920.

28. Vellante M, Baron-Cohen S, Melis M, et al. The "Reading the Mind in the Eyes" test: systematic review of psychometric properties and a validation study in Italy. Cogn Neuropsychiatry. 2013;18(4):326-354.

29. Yildirim EA, Kasar M, Güdük M. Gözlerden Zihin Okuma Testi’nin Türkçe Güvenirlik Çalışması [Investigation of the reliability of the "reading the mind in the eyes test" in a Turkish population]. Turk Psikiyatri Derg. 2011;22(3):177-186. Turkish.

30. Nunes P, Williams S, Sa B, Stevenson K. A study of empathy decline in students from five health disciplines during their first year of training. Int J Med Educ. 2011;2:12.

31. Hojat M, Mangione S, Nasca TJ, et al. An empirical study of decline in empathy in medical school. Med Educ. 2004;38(9):934-941.

32. Chen D, Lew R, Hershman W, Orlander J. A cross-sectional measurement of medical student empathy. J Gen Intern Med. 2007;22(10):1434-1438.
33. Reynolds WJ. The Measurement and Development of Empathy in Nursing. Abingdon: Routledge; 2017.

34. Radcliffe C, Lester H. Perceived stress during undergraduate medical training: a qualitative study. Med Educ. 2003;37(1):32-38.

35. Saipanish R. Stress among medical students in a Thai medical school. Med Teach. 2003;25(5):502-506.

36. Hojat M, Vergare MJ, Maxwell K, et al. The devil is in the third year: a longitudinal study of erosion of empathy in medical school. Acad Med. 2009;84(9):1182-1191.

37. Neumann M, Edelhäuser F, Tauschel D, et al. Empathy decline and its reasons: a systematic review of studies with medical students and residents. Acad Med. 2011;86(8):996-1009.

38. Newton BW, Barber L, Clardy J, Cleveland E, O'sullivan P. 2008 Is there hardening of the heart during medical school? Acad Med. 2008;83(3):244-249.

39. Boyle M, Williams B, Brown T, et al. Levels of empathy in undergraduate health science students. Internet J Med Educ. 2010;1(1):1-7.

40. Shapiro J. Walking a mile in their patients' shoes: empathy and othering in medical students' education. Philos Ethics Humanit Med. 2008;3(10):1-11.

41. Handford C, Lemon J, Grimm MC, Vollmer-Conna U. Empathy as a function of clinical exposure - reading emotion in the eyes. PLoS One. 2013;8(6):651-659.

42. Williams B, Brown T, Boyle M, McKenna L, Palermo C, Etherington J. Levels of empathy in undergraduate emergency health, nursing, and midwifery students: a longitudinal study. Adv Med Educ Pract. 2014;5:299-306.

43. Diehl M, Coyle N, Labouvie-Vief G. Age and sex differences in strategies of coping and defense across the lifespan. Psychol Aging. 1996; 11(1):127-139.

44. Phillips LH, MacLean RDJ, Allen R. Age and the understanding of emotions: neuropsychological and sociocognitive perspectives. J Gerontol B Psychol Sci Soc Sci. 2002;57(6):526-530.

45. Eisenberg N, Strayer J, editors. Empathy and its Development. Cambridge: Cambridge University Press; 1990.

46. Larson EB, Yao X. Clinical empathy as emotional labor in the patientphysician relationship. JAMA. 2005;293(9):1100-1106.

47. Kliszcz J, Hebanowski M, Rembowski J. Emotional and cognitive empathy in medical schools. Acad Med. 1998;73(5):541.

48. Tamres LK, Janicki D, Helgeson VS. Sex differences in coping behavior: a meta-analytic review and examination of relative coping. Pers Soc Psychol Rev. 2002;6(1):2-30.

49. Vollrath M, Torgersen S, Alnæs R. Personality as long-term predictor of coping. Pers Individ Dif. 1995;18(1):117-125.

50. Kardum I, Hudek-Knežević J. The relationship between Eysenck's personality traits, coping styles and moods. Pers Individ Dif. 1996;20(3): 341-350.

51. Chauhan M, Rai PK. Impact on self-talk and personality on empathy. Indian J Health Wellbeing. 2013;4(8):1497-1501.

52. Eysenck HJ. Manual of the Eysenck Personality Scales (EPS Adult). London: Hodder \& Stoughton; 1991.

53. Shiner R, Caspi A. Personality differences in childhood and adolescence: measurement, development, and consequences. J Child Psychol Psychiatry. 2003;44(1):2-32.
Neuropsychiatric Disease and Treatment

\section{Publish your work in this journal}

Neuropsychiatric Disease and Treatment is an international, peerreviewed journal of clinical therapeutics and pharmacology focusing on concise rapid reporting of clinical or pre-clinical studies on a range of neuropsychiatric and neurological disorders. This journa is indexed on PubMed Central, the 'PsycINFO' database and CAS,

\section{Dovepress}

and is the official journal of The International Neuropsychiatric Association (INA). The manuscript management system is completely online and includes a very quick and fair peer-review system, which is all easy to use. Visit http://www.dovepress.com/testimonials.php to read real quotes from published authors. 